Running head: Life goals and psychosocial adjustment to amputation

\title{
A prospective study of the importance of life goal characteristics and goal adjustment capacities in longer term psychosocial adjustment to lower limb amputation
}

Laura Coffey ${ }^{1,2}$, Pamela Gallagher ${ }^{1,2}$, and Deirdre Desmond ${ }^{2,3}$

${ }^{1}$ School of Nursing and Human Sciences, Dublin City University, Dublin, Ireland

${ }^{2}$ Dublin Psychoprosthetics Group, Dublin, Ireland

${ }^{3}$ Department of Psychology, National University of Ireland Maynooth, Co. Kildare, Ireland

Corresponding author: Prof. Pamela Gallagher, School of Nursing and Human Sciences, Dublin City University, Dublin 9, Ireland (tel: +353 1 7008958, e-mail:

pamela.gallagher@dcu.ie)

Keywords: Amputation; depression; goal importance; goal adjustment; prospective studies 


\begin{abstract}
Objective: To explore the life goal characteristics and goal adjustment capacities of persons with lower limb amputation on admission to rehabilitation, and to examine their efficacy as predictors of psychosocial outcomes 6 months postdischarge.
\end{abstract}

Design: Prospective, descriptive.

Setting: Two specialist inpatient rehabilitation facilities in Ireland.

Subjects: A consecutive sample of 64 patients with lower limb amputation.

Main measures: On admission to rehabilitation, life goal characteristics (goal importance, goal disturbance) were assessed using the Goal Facilitation Index and goal adjustment capacities (goal disengagement, goal re-engagement) were measured using the Goal Adjustment Scale. The Beck Depression Inventory-II and the Trinity Amputation and Prosthesis Experience Scales-Revised assessed depressive symptomatology and psychosocial adjustment to amputation at 6 months post-discharge. 
Results: The highest average importance ratings were assigned to goals associated with interpersonal relationships, independence, and subjective well-being. Goals related to physical limitations and disruptions in daily activities received the highest hindrance ratings. Goal importance $(\beta=-0.33)$ and goal disengagement $(\beta$ $=-0.29)$ on admission significantly predicted depressive symptomatology 6 months post-discharge $(p \leq .05)$. Goal importance $(\beta=0.32)$, goal disturbance $(\beta$ $=-0.26)$, and goal re-engagement $(\beta=-0.21)$ on admission significantly predicted general adjustment to lower limb amputation at 6 months post-discharge $(p \leq .05)$, while goal importance $(\beta=-0.32)$ and goal disturbance $(\beta=0.30)$ significantly predicted social adjustment $(p \leq .05)$.

Conclusions: Life goal characteristics and goal adjustment capacities on admission to rehabilitation predicted psychosocial outcomes 6 months post-discharge among individuals with lower limb amputation. 


\section{Clinical Messages:}

- Life goal characteristics and goal adjustment capacities on admission to rehabilitation predicted psychosocial outcomes among individuals with lower limb amputation 6 months post-discharge.

- Patient-led interventions targeted towards identifying and reducing disruptions in attaining valued goals and promoting goal disengagement could enhance adjustment in this patient group. 


\section{Introduction}

Individuals with lower limb loss can experience significant disruptions in many important life domains, including mobility (1), occupational status (2), social relations (3), participation (4), and mood (5). The main purpose of rehabilitation is to restore function; its success is often gauged in physical and functional terms only (1). Adaptation to acquired disability is a psychosocial as well as physical process, however, and it is argued that a more comprehensive biopsychosocial approach to rehabilitation is required $(6,7)$.

Self-regulation theory provides a useful framework for understanding motivation, affect, and goal-directed activity in rehabilitation contexts $(6,8-10)$. The central assumption is that human behaviour is organised around the pursuit of goals, which derive from core aspects of the self and are organised in a hierarchical structure. According to this perspective, goals at higher levels (life goals) relate to the person's roles or personal qualities and are broader and more conceptual in nature than those at lower levels. Goals are thought to give structure, coherence, and purpose to people's lives, and are thus of great significance for psychological well-being $(11,12)$.

Disturbances in the attainment of valued goals are associated with emotional distress and diminished quality of life (13-17). 
In order to restore emotional balance, it may be adaptive to disengage from goals that are no longer attainable and re-engage in alternative, meaningful goals $(11,18)$. Goal disengagement removes the person from the negative emotional consequences of repeated goal failure and frees up resources for the attainment of other goals. Goal reengagement establishes new goals to strive towards and returns the individual to being actively engaged in life. A stronger disposition for goal disengagement is associated with lower levels of psychological distress $(19,20)$, while being more disposed toward goal re-engagement is related to higher levels of positive affect $(21,22)$ and fewer depressive symptoms $(23,24)$.

Self-regulation theory is relevant to persons with lower limb amputation, as the impact of limb loss on physical and psychosocial functioning is likely to disrupt the attainment of goals in many life domains. This experience may also challenge people's outlook on life, leading to reprioritisation of existing goals and creation of new goals (13). Little is currently known about the types of goals that are most important to individuals with lower limb amputation, or those that are most affected by limb loss. Assessing the importance of different life goals and degree of difficulty experienced in their attainment may help to identify problems in areas of life that are highly valued in this patient group yet not usually addressed in rehabilitation. In addition, examining associations between the life goal characteristics and goal adjustment capacities of 
persons with amputation and their psychosocial outcomes prospectively could provide insight into how they may be supported in adapting goals to current abilities and maintaining psychological well-being in the long-term.

The objectives of the current study are: (1) to explore the life goal characteristics and goal adjustment capacities of persons with lower limb amputation on admission to rehabilitation; and (2) to examine their efficacy as predictors of psychosocial outcomes 6 months post-discharge.

\section{Methods}

Participants were recruited from two urban hospitals in Ireland that offer specialised, interdisciplinary inpatient rehabilitation programmes for individuals with lower limb amputation. Ethics Committees at both hospitals approved the study protocol. Persons aged $\geq 18$ years who were admitted between February 2010 and July 2011 with major lower limb amputation (i.e. above ankle level) for which inpatient rehabilitation services had not previously been provided, and who had sufficient proficiency in English for the demands of the study, were eligible to participate. Patients were excluded if they had severe cognitive impairment, indicated by a Mini Mental State Examination (25) score of $<18$, or were deemed unsuitable due to previous or current history of psychiatric 
morbidity. Potential participants were identified by the consultant in charge of the programme in each hospital. Patients were initially approached and given an information sheet describing the study. Those who agreed to take part signed a consent form. Questionnaires were administered by the researcher (L.C.) in a structured interview format. Six months after discharge, questionnaires were either delivered by post for self-completion or administered by the same researcher in the participant's home.

Participants' age, gender, education level, marital status, and living situation were recorded on admission to rehabilitation. Clinical data regarding when the amputation was carried out, cause and level of amputation, presence of co-morbidities, and residual and phantom limb pain were also documented on admission. Average intensity of amputation-related pain was assessed using a single item from the Brief Pain Inventory (26). Participants rated their average pain intensity on a numeric rating scale ranging from 0 ('no pain') to 10 ('pain as bad as you can imagine').

The Goal Facilitation Inventory (27) was completed at both time points. This measure consists of 26 higher-order life goals. Participants firstly evaluated the importance of each goal in their everyday lives on a 5-point Likert scale ranging from 'not at all important' (1) to 'very important' (5). Scores on these items were summed to obtain a 
goal importance score. On a scale ranging from 1 ('not at all hindered') to 5 ('completely hindered'), participants then reported the extent to which they were currently hindered in attaining each goal as a result of their amputation. Finally, a goal disturbance score was calculated by multiplying the goal importance score for each item by its goal hindrance score and summing the resulting 26 product scores. This instrument demonstrates good internal consistency (13). Cronbach's alphas were 0.84 for goal importance and 0.93 for goal disturbance in the current study.

The Goal Adjustment Scale (18) was completed at both time points. This scale consists of ten items assessing how respondents typically react if they have to stop pursuing an important goal in their life. Four items assess the tendency to disengage from unattainable goals; six items measure the capacity to re-engage in new goals. Items are rated on Likert scales ranging from 1 ('strongly disagree') to 5 ('strongly agree'). This measure has acceptable reliability and validity $(18,22)$. In the present study, Cronbach's alpha values of 0.70 and 0.91 were observed for the disengagement and re-engagement subscales, respectively.

The Beck Depression Inventory-II (28), a 21-item self-report measure of depressive symptomatology, was completed at both study time points. Total scores range from 0 to 63 ; higher scores denote greater depressive symptomatology. This scale has well- 
established psychometric properties (29). The Cronbach's alpha value in the present sample was 0.91 .

The Trinity Amputation and Prosthesis Experience Scale-Revised (30) is a 64-item multidimensional self-measurement instrument assessing adjustment to amputation and prosthesis use. The psychosocial adjustment scale was employed in the present study; it consists of three 5-item subscales measuring general adjustment, social adjustment, and adjustment to limitations. Items are rated on 4-point scales ranging from 'strongly disagree' (1) to 'strongly agree' (4); higher scores indicate better adjustment. This measure demonstrates adequate psychometric properties (30). In the present study, Cronbach's alpha values of $0.91,0.96$, and 0.81 were observed for the general adjustment, social adjustment, and adjustment to limitations subscales, respectively.

Statistical analyses were conducted using the Statistical Package for the Social Sciences Version 20 (IBM, 2010). Goal disturbance, depressive symptomatology, and social adjustment scores were not normally distributed and were transformed to better meet the assumptions of multiple regression. Marital status (with/without partner), living situation (living alone/with others), and cause of amputation (chronic/acute) were recoded into dichotomous dummy variables. Life goals were ranked in terms of their mean importance, hindrance, and disturbance (importance $\mathrm{x}$ hindrance) scores on 
admission to rehabilitation. Relationships between predictor and outcome variables were examined using hierarchical multiple regression analyses. Baseline outcome scores were controlled for in the first step. Given the limited sample size at 6 months post-discharge, only sociodemographic and/or clinical variables significantly correlated with the outcomes $(p \leq .05)$ were controlled for in the second step. Goal importance and goal disturbance were entered in the third step, followed by goal disengagement and reengagement in the fourth step. None of the assumptions of multiple regression were violated.

\section{Results}

Of the 113 patients eligible to participate, 12 declined to participate and 3 were discharged prior to meeting with the researcher. The remaining 98 patients agreed to take part and completed questionnaires on admission to rehabilitation; 64 (65\%) of these participants also completed questionnaires 6 months after discharge. For the final sample $(N=64)$, participants' ages ranged from 28 to 89 years $(M=63.56, S D=11.96)$. Most were male $(n=53)$, married $(n=33)$, had primary $(n=29)$ or secondary $(n=21)$ level education only, and lived with their partner $(n=32)$. Thirty-one participants had below-knee amputations, 28 had an above-knee amputation, and 5 had bilateral amputations. For most participants, the cause of amputation was chronic (i.e., peripheral 
vascular disease, diabetes, or cancer $)$ in nature $(n=50)$. Time elapsed since amputation ranged from 6 to 260 weeks, with a median of 20 weeks $(M=31.56, S D=42.84)$. Fiftyfour participants experienced at least one comorbid health condition; the most common comorbidities were cardiac problems $(n=42)$ and diabetes $(n=30)$. Forty-eight participants experienced phantom limb pain, and 20 reported residual limb pain. The average intensity of amputation-related pain experienced was $2.30(S D=2.02)$.

Descriptive statistics for the predictor and outcome variables are displayed in Table 1.

*** insert Table 1 here***

Tables 2-4 display the top ten Goal Facilitation Inventory items ranked in terms of their mean importance, hindrance, and disturbance ratings on admission to rehabilitation. 'Being healthy' was the most important life goal in this sample on average. All 64 participants rated this goal as either 'important' or 'very important'. 'Keeping up my self-confidence' $(n=63)$ and 'treating others fairly' $(n=63)$ were the second and third most important life goals, respectively.

\footnotetext{
*** insert Table 2 here $* * *$
} 
On average, participants reported experiencing the greatest hindrance in 'having my daily activities run smoothly'. This was followed by 'experiencing bodily pleasures' and 'discovering new things'.

$* * *$ insert Table 3 here***

The highest mean goal disturbance scores on admission to rehabilitation were given to 'ensuring my safety', 'being healthy', and 'having my daily activities run smoothly'.

*** insert Table 4 here***

Associations between sociodemographic and clinical characteristics and depressive symptomatology, general adjustment, and adjustment to limitations at 6 months postdischarge were non-significant. Social adjustment was significantly associated with presence of residual limb pain $(r=0.32)$, average pain intensity $(r=0.27)$, and education level $(F=4.70, d f=2,61, p=.013)$; these variables were controlled for in the second step of the regression model predicting this outcome.

The hierarchical regression analyses were significant for each of the outcomes assessed at 6-month follow-up (see Table 5). Goal importance and goal disengagement emerged 
as significant predictors of depressive symptomatology, in addition to baseline scores. General adjustment was independently predicted by baseline scores, goal importance, goal disturbance, and goal re-engagement. Goal importance and goal disturbance were also significant predictors of social adjustment, along with baseline scores and having primary level education only. Baseline scores were the only significant predictor to emerge for adjustment to limitations.

$$
* * * \text { insert Table } 5 \text { here } * * *
$$

\section{Discussion}

The most significant finding of the present study was that life goal characteristics and goal adjustment capacities on admission to rehabilitation predicted depressive symptomatology and psychosocial adjustment to limb loss 6 months after discharge among individuals with lower limb amputation. Specifically, higher goal importance predicted fewer symptoms of depression and better general and social adjustment to amputation, while higher goal disturbance predicted poorer general and social adjustment outcomes. A stronger disposition towards goal disengagement predicted lower depressive symptomatology. Contrary to expectations, stronger goal reengagement tendencies were predictive of poorer general adjustment. Overall, these 
findings support many assumptions of self-regulation theory. This perspective offers a valuable account of the processes underlying psychosocial adjustment to lower limb amputation and merits further application to persons with acquired physical impairment.

Certain limitations should be considered when interpreting the results. Participants were recruited from a prosthetic rehabilitation programme and are likely to represent a healthier and more able-bodied sector of this population. Many individuals who undergo amputation never attend formal rehabilitation due to age or ill health (34). Recruiting participants from hospital settings following amputation surgery might have increased the generalizability of findings. Previous authors have highlighted significant challenges in such an approach, however (35). The use of self-report measures leaves open the possibility that response biases may have influenced scores. Qualitative interviews could be employed to bolster questionnaire findings and elaborate interesting issues arising from the quantitative data (36). The timeframe of the study, from rehabilitation admission up to 6 months post-discharge, was limited; more extensive longitudinal studies are required.

This is the first study to examine life goals in people with lower limb amputation. Goals most highly valued on admission to rehabilitation related to subjective well-being (e.g., 'being healthy', 'keeping up my self-confidence'), interpersonal relationships (e.g., 
'supporting others', 'feeling connected to the people around me'), and maintaining independence (e.g., 'making my own decisions in life', 'ensuring my own safety'). This is in keeping with previous studies of individuals with acquired physical impairment; life goals relating to partner/family and personal care tend to be valued above those contingent on physical functioning $(16,17)$ and given significantly higher importance ratings compared with healthy controls $(14,15)$. These preferences might reflect the gradual 'scaling back' or disengagement from unattainable goals that occurs in adaptive selfregulation $(18,32)$. Greatest hindrance was experienced in goals indicative of the physical limitations posed by lower limb loss and associated disruptions in independence (e.g., 'meeting a challenging standard of performance', 'fulfilling my duties to others') and everyday activities (e.g., 'having daily activities run smoothly', 'doing creative things',). This was expected, given that participants had not yet completed their rehabilitation programme. Longitudinal assessment of goal hindrance in this population following rehabilitation is required.

Goal disturbance ratings, which were weighted for importance, indicated that participants were most concerned by disturbances they experienced in goals relating to their independence (e.g., 'ensuring my safety', 'meeting a challenging standard of performance') and well-being (e.g., 'keeping up my self-confidence', 'feeling relaxed'). These findings highlight the importance of considering patients' psychological as well as 
physical adjustment to limb loss during the rehabilitation process. Interestingly, 'experiencing bodily pleasures' did not feature among the top ten goals in terms of goal disturbance ratings, despite its high goal hindrance ranking. This suggests that although participants' sexual functioning was hindered by their limb loss, this area of their lives was considered of less importance than others on admission to rehabilitation, which may indicate self-protective goal disengagement processes at work $(18,32)$. Nonetheless, these findings indicate the negative impact of amputation on sexual functioning, and emphasise the importance of education and support in this under-reported domain during rehabilitation (33).

The importance participants afforded their goals on admission to rehabilitation predicted level of depressive symptoms and extent of general and social adjustment to amputation 6 months post-discharge. This corresponds with cross-sectional studies in which higher goal importance was associated with less emotional distress and greater life satisfaction in people with chronic illness and disability $(13,15-17)$. These findings support the assumption that life goals, particularly those that are highly valued, are closely linked with people's sense of self and imbue their lives with meaning and purpose (11). In addition, higher goal disturbance scores on admission were predictive of poorer general and social adjustment at 6-month follow-up, which provides further support for the notion that disruptions in goal attainment have affective consequences (13-16). 
Having a stronger disposition toward goal disengagement on admission to rehabilitation predicted fewer depressive symptoms 6 months after discharge. This is in keeping with previous studies of goal adjustment capacities in different patient groups $(19,20)$, and supports the notion that adverse affective consequences associated with illness and disability can be reduced if people disengage from goals that are no longer attainable (11, 18). Contrary to expectations, higher goal re-engagement on admission to rehabilitation was predictive of poorer general adjustment at follow-up. This finding diverges from the literature; goal re-engagement has repeatedly been linked with greater positive affect (21, $22)$ and fewer symptoms of depression $(23,24)$. It is possible that goal re-engagement is acting as a suppressor variable in this analysis, as its correlation with general adjustment was non-significant $(r=.07)$. Suppressor variables improve prediction of outcome variables due to their correlations with other predictor variables, despite low correlations with the outcome variables themselves (31).

Setting and achieving goals is an essential component of the rehabilitation process (37). Patients are more likely to engage in rehabilitation if treatment goals are personally meaningful and relevant (8), yet they are often excluded from the goal selection process (38), even though their valued goals may differ significantly from those of the rehabilitation team (39). The present study indicates the potential value of assessing the 
life goal characteristics of persons with lower limb amputation early in the rehabilitation process. This information could be used not only to screen for individuals at risk for poor psychosocial outcomes in the longer term, but also to identify areas of life in which they are experiencing difficulties that may not have been considered by the rehabilitation team. Indeed, the goals that received the highest importance ratings in this study are rarely considered in the rehabilitation process, which focuses on physical aspects of recovery (16, 39). Greater involvement of patients in the goal setting process is associated with decreased anxiety (10), increased self-efficacy (40), greater adherence to treatment (41), and greater maintenance of therapeutic gains (42), and might also allow patients to develop more realistic expectations concerning recovery (7).

Self-regulation theory might prove valuable in guiding patients' participation in goal setting $(8,9)$. Sivaraman Nair $(8)$ argues that coping with loss of valued goals and refocusing on more attainable goals are essential for successful rehabilitation, and proposes that the rehabilitation process should begin with identification of the patient's goals, followed by the step of distinguishing achievable from unachievable goals. Rehabilitation goals can then be set so that the patient is enabled to work on achievable goals and to attempt to restructure or deal with the loss of goals that no longer seem attainable. Administration of a measure such as the Goal Facilitation Inventory (27) could aid in this process. Alternatively, a goal elicitation procedure such as identity-oriented goal training 
could be employed $(9,43)$, in which patients select a person they aspire towards being like and use this 'role model' as a means of stimulating thought about their own personally valued goals. Self-regulation theory might also usefully guide the development of rehabilitation-based interventions to promote long-term psychosocial adjustment to amputation. The implementation of existing interventions such as goal management training $(9,44)$ or Acceptance and Commitment Therapy (45) might help to reduce goal disturbance by enabling patients to strive towards their valued goals or disengage from those that are no longer attainable, thus promoting adjustment.

\section{References}

1. van Velzen JM, van Bennekom, C. A. M., Polomski W, Slootman JR, van dW, Houdijk H. Physical capacity and walking ability after lower limb amputation: A systematic review. Clin Rehabil. 2006;20(11):999-1016.

2. Burger H, Marinček Č. Return to work after lower limb amputation. Disabil Rehabil. 2007;29(17):1323-9. 
3. Williams RM, Ehde DM, Smiths DG, Czerniecki JM, Hoffman AJ, Robinson LR. A two-year longitudinal study of social support following amputation. Disabil Rehabil. 2004;26(14):862-74.

4. Gallagher P, O’Donovan MA, Doyle A, Desmond D. Environmental barriers, activity limitations and participation restrictions experienced by people with major limb amputation. Prosthet Orthot Int. 2011;35(3):278-84.

5. Singh R, Ripley D, Pentland B, Todd I, Hunter J, Hutton L, et al. Depression and anxiety symptoms after lower limb amputation: The rise and fall. Clin Rehabil. 2009;23(3):281-6.

6. Brands IMH, Wade DT, Stapert SZ, van Heugten CM. The adaptation process following acute onset disability: An interactive two-dimensional approach applied to acquired brain injury. Clin Rehabil. 2012;26(9):840-52.

7. Playford ED, Siegert R, Levack W, Freeman J. Areas of consensus and controversy about goal setting in rehabilitation: A conference report. Clin Rehabil. 2009;23(4):33444.

8. Sivaraman Nair KP. Life goals: The concept and its relevance to rehabilitation. Clin Rehabil. 2003;17(2):192-202. 
9. McPherson KM, Kayes N, Weatherall M. A pilot study of self-regulation informed goal setting in people with traumatic brain injury. Clin Rehabil. 2009;23(4):296-309.

10. McGrath JR, Adams L. Patient-centered goal planning: A systemic psychological therapy? Topics Stroke Rehabil. 1999;6(2):43-50.

11. Carver CS, Scheier MF. On the self-regulation of behavior. Cambridge: Cambridge University Press; 1998.

12. Emmons RA. Personal strivings: An approach to personality and subjective wellbeing. J Pers Soc Psychol. 1986;51(5):1058-68.

13. Boersma SN, Maes S, van Elderen T. Goal disturbance predicts health-related quality of life and depression 4 months after myocardial infarction. Brit J Health Psychol. 2005;10(4):615-30.

14. Conrad N, Doering BK, Rief W, Exner C. Looking beyond the importance of life goals. The personal goal model of subjective well-being in neuropsychological rehabilitation. Clin Rehabil. 2010;24(5):431-43.

15. McNamara P, Durso R, Harris E. Life goals of patients with Parkinson's disease: A pilot study on correlations with mood and cognitive functions. Clin Rehabil. 2006;20(9):818-26. 
16. Boerner K, Cimarolli VR. Optimizing rehabilitation for adults with visual impairment: Attention to life goals and their links to well-being. Clin Rehabil. 2005;19(7):790-8.

17. Nair K, Wade DT. Life goals of people with disabilities due to neurological disorders. Clin Rehabil. 2003;17(5):521-7.

18. Wrosch C, Scheier MF, Miller GE, Schulz R, Carver CS. Adaptive self-regulation of unattainable goals: Goal disengagement, goal reengagement, and subjective wellbeing. Person Soc Psychol Bull. 2003;29(12):1494-508.

19. Dunne E, Wrosch C, Miller GE. Goal disengagement, functional disability, and depressive symptoms in old age. Health Psychol. 2011;30(6):763-70.

20. Kraaij V, van der Veek SMC, Garnefski N, Schroevers M, Witlox R, Maes S. Coping, goal adjustment, and psychological well-being in HIV-infected men who have sex with men. AIDS Patient Care STDS. 2008;22(5):395-402.

21. Schroevers M, Kraaij V, Garnefski N. How do cancer patients manage unattainable personal goals and regulate their emotions? Br J Health Psychol. 2008;13(3):551-62.

22. Wrosch C, Sabiston CM. Goal adjustment, physical and sedentary activity, and well-being and health among breast cancer survivors. Psycho-Oncol. 2012;22(3):581-9. 
23. Garnefski N, Kraaij V. Cognitive coping and goal adjustment are associated with symptoms of depression and anxiety in people with acquired hearing loss. Int $\mathbf{J}$ Audiol. 2012;51(7):545-50.

24. Kraaij V, Garnefski N, Schroevers MJ, Weijmer J, Helmerhorst F. Cognitive coping, goal adjustment, and depressive and anxiety symptoms in people undergoing infertility treatment: A prospective study. J Health Psychol. 2010;15(6):876-86.

25. Folstein MF, Folstein SE, McHugh PR. "Mini-mental state": A practical method for grading the cognitive state of patients for the clinician. J Psychiatr Res. 1975;12(3):18998.

26. The Brief Pain Inventory: User guide [Internet].; 2009. Available from: http://www.mdanderson.org/education-and-research/departments-programs-andlabs/departments-and-divisions/symptom-research/symptom-assessment-tools/briefpain-inventory-users-guide.html.

27. Maes S, ter Doest L, Gebhardt W. The Goal Facilitation Inventory: Factor structure and psychometric properties. Leiden University: Clinical and Health Psychology Section; 2002.

28. Beck AT, Steer RA, Brown GK. Beck Depression Inventory manual. 2nd edn. San Antonio, TX: Psychological Corporation; 1996. 
29. Dozois DJA, Dobson KS, Ahnberg JL. A psychometric evaluation of the Beck Depression Inventory-II. Psychol Assess. 1998;10(2):83-9.

30. Gallagher P, Franchignoni F, Giordano A, MacLachlan M. Trinity Amputation and Prosthesis Experience Scales: A psychometric assessment using classical test theory and Rasch analysis. Am J Phys Med Rehabil. 2010;89(6):487.

31. Tzelgov J, Henik A. Suppression situations in psychological research: Definitions, implications, and applications. Psychol Bull. 1991;109(3):524-36.

32. Carver CS, Scheier MF. Scaling back goals and recalibration of the affect system are processes in normal adaptive self-regulation: Understanding 'response shift' phenomena. Soc Sci Med. 2000;50(12):1715-22.

33. Geertzen JHB, Van Es CG, Dijkstra PU. Sexuality and amputation: A systematic literature review. Disabil Rehabil. 2009;31(7):522-7.

34. Dillingham TR, Pezzin LE, MacKenzie EJ. Discharge destination after dysvascular lower-limb amputations. Arch Phys Med Rehabil. 2003;84(11):1662-8.

35. Phelps LF, Williams RM, Raichle KA, Turner AP, Ehde DM. The importance of cognitive processing to adjustment in the first year following amputation. Rehabil Psychol. 2008;53(1):28-38. 
36. Johnson RB, Onwuegbuzie AJ. Mixed methods research: A research paradigm whose time has come. Educ Researcher. 2004;33(7):14-26.

37. Scobbie L, Dixon D, Wyke S. Goal setting and action planning in the rehabilitation setting: Development of a theoretically informed practice framework. Clin Rehabil. 2011;25(5):468-82.

38. Rosewilliam S, Roskell CA, Pandyan A. A systematic review and synthesis of the quantitative and qualitative evidence behind patient-centred goal setting in stroke rehabilitation. Clin Rehabil. 2011;25(6):501-14.

39. Bloom LF, Lapierre NM, Wilson KG, Curran D, DeForge DA, Blackmer J. Concordance in goal setting between patients with multiple sclerosis and their rehabilitation team. Am J Phys Med Rehabil. 2006;85(10):807-13.

40. Coppack RJ, Kristensen J, Karageorghis CI. Use of a goal setting intervention to increase adherence to low back pain rehabilitation: A randomized controlled trial. Clin Rehabil. 2012;26(11):1032-42.

41. Levack WM, Taylor K, Siegert RJ, Dean SG, McPherson KM, Weatherall M. Is goal planning in rehabilitation effective? A systematic review. Clin Rehabil. 2006;20(9):739-55. 
42. Stuifbergen AK, Becker H, Timmerman GM, Kullberg V. The use of individualized goal setting to facilitate behavior change in women with multiple sclerosis. J Neurosci Nurs. 2003;35(2):94-106.

43. Ylvisaker M, Mcpherson K, Kayes N, Pellett E. Metaphoric identity mapping: Facilitating goal setting and engagement in rehabilitation after traumatic brain injury. Neuropsychol Rehabil. 2008;18(5-6):713-41.

44. Levine B, Robertson IH, Clare L, Carter G, Hong J, Wilson BA, et al. Rehabilitation of executive functioning: An experimental-clinical validation of goal management training. J Int Neuropsychol Soc. 2000;6(3):299-312.

45. Hayes SC, Strosahl K, Wilson KG. Acceptance and commitment therapy: An experiential approach to behavior change. New York: Guilford Press; 1999. 
Table 1. Descriptive statistics for predictor and outcome variables.

\begin{tabular}{|c|c|c|c|c|c|c|}
\hline & Variable & Possible range & Minimum value & Maximum value & $M$ & $S D$ \\
\hline 1. & Goal importance & $26-130$ & 79 & 130 & 102.39 & 10.28 \\
\hline 2. & Goal disturbance & $26-650$ & 95 & 386 & 180.30 & 72.26 \\
\hline 3. & Goal disengagement & $1-5$ & 1 & 4.75 & 2.85 & 0.85 \\
\hline 4. & Goal-re-engagement & $1-5$ & 1.83 & 5 & 3.58 & 0.81 \\
\hline 5. & Depressive symptomatology & $0-63$ & 0 & 37 & 8.85 & 8.84 \\
\hline 6. & General adjustment & $1-4$ & 1.8 & 4 & 3.20 & 0.57 \\
\hline 7. & Social adjustment & $1-4$ & 1 & 4 & 3.38 & 0.62 \\
\hline 8. & Adjustment to limitations & $1-4$ & 1 & 3 & 1.91 & 0.55 \\
\hline
\end{tabular}

Note: The means and standard deviations presented for goal disturbance, depressive symptomatology and social adjustment were calculated prior to transformation. 
Table 2. Top ten goals in terms of mean goal importance ratings on admission to rehabilitation $(N=64)$.

\section{Mean $S D$}

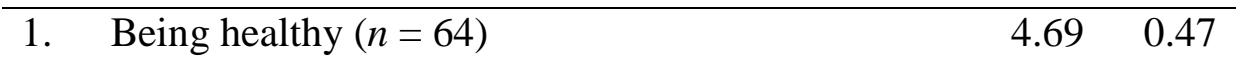

2. Keeping up my self-confidence $(n=63)$

$4.53 \quad 0.53$

3. Treating others fairly $(n=63)$

$4.48 \quad 0.53$

4. Making my own decisions in life $(n=63)$

$4.47 \quad 0.59$

5. Ensuring my safety $(n=61)$

$4.36 \quad 0.68$

6. Fulfilling my duties to others $(n=61)$

$4.30 \quad 0.61$

$7=\quad$ Feeling relaxed $(n=58)$

$4.27 \quad 0.72$

$7=$ Supporting others $(n=60)$

$4.27 \quad 0.67$

9. Feeling like I belong here $(n=59)$

$4.25 \quad 0.67$

10. Feeling connected to the people around me $(n=58) \quad 4.23 \quad 0.71$ 
Table 3. Top ten goals in terms of mean goal hindrance ratings on admission to rehabilitation $(N=64)$.

Mean SD

\begin{tabular}{llll}
\hline 1. Having my daily activities run smoothly $(n=38)$ & 2.28 & 1.30
\end{tabular}

2. $\quad$ Experiencing bodily pleasures $(n=32) \quad 2.22 \quad 1.43$

3. Discovering new things $(n=37) \quad 2.17 \quad 1.18$

4. Meeting a challenging standard of performance $(n=33) \quad 2.14 \quad 1.22$

$5=\quad$ Fulfilling my duties to others $(n=32) \quad 2.11 \quad 1.20$

$5=$ Experiencing excitement $(n=35) \quad 2.11 \quad 1.20$

$\begin{array}{lll}\text { 7. Doing creative things }(n=32) & 2.02 & 1.22\end{array}$

8. Ensuring my safety $(n=31) \quad 2.00 \quad 1.14$

9. Doing things better than others $(n=28) \quad 1.92 \quad 1.23$

10. Being healthy $(n=29) \quad 1.91 \quad 1.14$ 
Table 4. Top ten goals in terms of mean goal disturbance* ratings on admission to rehabilitation $(N=64)$.

\section{Mean $S D$}

1. $\quad$ Ensuring my safety

$9.39 \quad 5.15$

2. Being healthy

$9.31 \quad 5.49$

3. Having my daily activities run smoothly

4. Keeping up my self-confidence

5. Discovering new things

6. Meeting a challenging standard of performance

7. Fulfilling my duties to others

8. Doing things better than others

9. Doing creative things

10. Feeling relaxed

$7.78 \quad 3.93$

* goal disturbance $=$ goal importance $\mathrm{x}$ goal hindrance 
Table 5. Summary of hierarchical regression analyses predicting depressive symptomatology and psychosocial adjustment.

\begin{tabular}{|c|c|c|c|c|c|c|c|c|}
\hline \multirow[t]{2}{*}{ Variable } & \multicolumn{2}{|c|}{ Depressive symptomatology } & \multicolumn{2}{|c|}{ General adjustment } & \multicolumn{2}{|c|}{ Social adjustment } & \multicolumn{2}{|c|}{ Adjustment to limitations } \\
\hline & $\beta$ & $\Delta R^{2}$ & $\beta$ & $\Delta R^{2}$ & $\beta$ & $\Delta R^{2}$ & $\beta$ & $\Delta R^{2}$ \\
\hline Step 1 & & $.450 * * *$ & & $.397^{* * *}$ & & $.284^{* * *}$ & & $.178^{* * *}$ \\
\hline Baseline outcome scores & $0.57 * * *$ & & $0.55^{* * *}$ & & $-0.35 * * *$ & & $0.43 * *$ & \\
\hline Step 2 & & - & & - & & $.157^{* *}$ & & - \\
\hline Education (primary) & - & & - & & $0.45^{* * *}$ & & - & \\
\hline Education (secondary) & - & & - & & 0.17 & & - & \\
\hline Residual limb pain & - & & - & & 0.11 & & - & \\
\hline Average pain intensity & - & & - & & 0.11 & & - & \\
\hline Step 3 & & $.058^{*}$ & & $.081 *$ & & $.109 * *$ & & .002 \\
\hline Goal importance & $-0.33 * * *$ & & $0.32 * *$ & & $-0.32 * *$ & & -0.01 & \\
\hline Goal disturbance & 0.10 & & $-0.26^{*}$ & & $0.30 * *$ & & -0.01 & \\
\hline Step 4 & & $.076^{* * *}$ & & .036 & & .034 & & .015 \\
\hline Goal disengagement & $-0.29 * *$ & & 0.04 & & 0.13 & & 0.12 & \\
\hline Goal re-engagement & 0.05 & & $-0.21^{*}$ & & 0.15 & & 0.02 & \\
\hline Adjusted $R^{2}$ & & .548 & & .472 & & .515 & & .125 \\
\hline
\end{tabular}

Note: An inverse transformation was performed on social adjustment, and the direction of scores for this variable should be reversed before interpretation. * $p \leq .05 ; * * p \leq .01 ; * * * \leq .001$ 